HISPANIA. Revista Española de Historia, 2011, vol. LXXI, núm. 239, septiembre-diciembre, págs. 789-818, ISSN: 0018-2141

\title{
¿FUE EL SECTOR ELÉCTRICO UN GRAN BENEFICIARIO DE «LA POLÍTICA HIDRÁULICA» ANTERIOR A LA GUERRA CIVIL? (1911-1936)1
}

\section{ISABEL BARTOLOMÉ RODRÍGUEZ}

Instituto Superior de Ciências do Trabalho e da Empresa - ISCTE

RESUMEN: El análisis del discurso hidráulico español constituye un clásico de nuestra historiografía al que, últimamente, se han añadido fecundas investigaciones sobre las realizaciones de la política bidráulica en algunas cuencas. Asimismo, en los últimos veinte años, nuestro conocimiento sobre los antecedentes de la industria eléctrica y sobre la dotación de infraestructuras de la economía española ba mejorado sustancialmente. Se sabe, pues, que la expansión hidroeléctrica en España fue decisiva antes de la guerra civil, cuando en el agua tenía su origen más del 90 por 100 de la electricidad producida y una cuarta parte del total de la energía consumida en el país. Conocemos también que en España, como en otros países orientados al aprovechamiento bidroeléctrico, se otorgaron ayudas públicas para la construcción de infraestructuras para el embalse de agua por efecto de la Ley Gasset y durante la Dictadura. Sabemos de la importancia de estos auxilios en Francia o en Italia, pero se desconoce enteramente el alcance de estas ayudas públicas en España.

Este artículo procura el esclarecimiento de esa cuestión, dedicando sus tres primeras secciones a explicar la oportunidad y finalidad de dichos auxilios y las dos siguientes a examinar sus realizaciones. Se sigue tanto un procedimiento directo como otro indirecto para desglosar cuáles fueron efectivamente las ayudas recibidas por las empresas bidroeléctricas. Aqui se concluye que el empuje público a la construcción de embalses y diques de aprovechamiento bidroeléctrico fue durante este período tan leve como corto el vuelo de la orientación industrialista de la política hidráulica en España.

Isabel Bartolomé Rodríguez es becaria post-doctoral en el Instituto Superior de Ciências do Trabalho e da Empresa - ISCTE. Dirección para correspondencia: Instituto Superior de Ciências do Trabalho e da Empresa - ISCTE, Departamento de História, Avenida das Forças Armadas s/n, 1649-026-Lisboa Portugal.Correo electrónico: ibrez@iscte.pt.

${ }^{1}$ Siglas: Archivo Banco de España (ABE); Archivo Unión Electrica Madrileña (AUEM); Cámara Oficial de Productores y Distribuidores de Electricidad (COPDE); Empresa Nacional Hidroeléctrica del Ribagorzana (ENHER); Hidroeléctrica Española (HE); Revista de Obras Públicas (ROP); Unidad Eléctrica Española S.A. (UNESA); Unión Eléctrica Madrileña (UEM). 
Palabras clave: Embalses. Presas. Hidroelectricidad. Política Hidráulica. Industria eléctrica. España.

DID THE SPANISH ELECTRICITY SECTOR GREATLY BENEFIT FROM THE 'HYDRAULIC POLICY' BEFORE THE CIVIL WAR? (1911-1936)

ABSTRACT: The discussion on the bydraulics policy in the 20th century is a classic of Spanish historiography, and has been expanded thanks to productive investigations on bydraulic policy in some basins. Over the course of the last 20 years, our understanding of these past events in the electrical industry and the contribution of infrastructure from the Spanish economy has improved greatly. Thus, the pre-civil war period has been shown to be the most relevant phase of expansion of hydroelectricity in Spain. From 1911 to 1936, 90 percent of the electricity produced in Spain was water-powered and it represented 25 percent of the total energy consumption in the country. We also know that in Spain, like in other countries equipped to take advantage of hydroelectric power, public grants were awarded in order to build reservoir infrastructure under the Gasset Law and during the dictatorship. We know the importance of this aid in France and Italy, but its total impact in Spain is unknown.

This article tries to clarify this issue and the first three sections are dedicated to exploring the opportunity and finality of said aid, while the next two sections examine its application. Direct and indirect procedures are used to break down the exact nature of aid received by the bydroelectric companies. The conclusion reached is that public backing for the construction of reservoirs and dikes was, during this period, as slight as the period of industrialist orientation of Spain's bydraulic policies was short.

KEY WORDS: Reservoirs. Dams. Hydroelectricity. Hydraulics Policy. Electrical Industry. Spain.

Entre ambas guerras mundiales, las primeras políticas gubernamentales de fomento eléctrico promovieron el tendido de redes de transmisión y la construcción de presas en los países hidroeléctricos. Con ambas políticas, se perseguía un objetivo similar: mejorar el rendimiento de los sistemas de suministro eléctrico. Las redes de interconexión favorecían la integración entre unidades de generación y entre mercados distantes entre sí, cuyos máximos de producción y consumo podían de ese modo compensarse. Los embalses almacenaban agua a gran escala, cuyo caudal alimentaba con regularidad grandes unidades de generación hidroeléctrica. La dimensión de las presas, enormes construcciones civiles, y la polivalencia de su uso abrieron paso a su consideración como infraestructura pública, susceptible pues de recibir financiación del Estado. De hecho, la expansión de la hidroelectricidad a gran escala en Europa durante el decenio de 1920 estribó en buena medida en la inversión pública, bien directamente, o bien a través de avales ${ }^{2}$.

${ }^{2}$ Estos procesos corrieron en paralelo al aumento de la intervención pública en estos sectores. Véase MORSEL, Henri, «Étude comparée des nationalisations de l'électricité en Europe occidentale après la Deuxième Guerre mondiale», en TREDE, Monique, Électricité et électrification dans le monde, 
Se observan dos núcleos de explotación hidroeléctrica en la Europa anterior a la II Guerra Mundial: el escandinavo, donde la abundancia de recursos hidráulicos favoreció una intensa y temprana electrificación; y el conformado por los países del Sur de Europa, donde la escasez de carbón impulsó la explotación de sus saltos de agua ${ }^{3}$. En ambos núcleos, se transitó del empleo de recursos hídricos dispersos y que precisaban escasas inversiones de acondicionamiento al aprovechamiento de saltos en cadena y a la construcción de grandes presas de almacenamiento. Mientras que en la primera etapa la iniciativa correspondió a la iniciativa privada o a los ayuntamientos, la intervención de los poderes públicos fue decisiva en el cambio de escala de la explotación hidroeléctrica de la posguerra europea. En Noruega, Suecia y Finlandia el protagonismo inicial de los municipios fue cediendo paso a sus respectivas administraciones centrales, que llegaron a hacerse propietarias de los principales aprovechamientos ${ }^{4}$. En el Sur de Europa, el suministro eléctrico se mantuvo en

París, P.U.F, 1992, págs. 441-457; Revisados por SegreTO, Luciano, «Ciento veinte años de electricidad. Dos mundos diferentes y parecidos», en ANES, Gonzalo (dir.), Un siglo de luz. Historia empresarial de Iberdrola, Madrid, El Viso, 2006, págs. 17-54; LANTHIER, Pierre, «Les autorités publiques et l'électrification, de 1870 à 1940. Une comparaison européenne», Annales Historiques de l'électricité, 4 (2006), págs. 125-144; SUDRIÀ, Carles, «El Estado y el sector eléctrico español bajo el franquismo: regulación y empresa pública», en GómEZ MENDOZA, Antonio, SudRì̀, Carles y PueYO, Javier, Electra y el Estado, vol. 1, Madrid, Thomson-Civitas, 2007, págs. 21-60; y Hausman, William J., Hertner, Peter y Wilkins, Mira, Global electrification. Multinational Enterprise and International Finance in the History of Light and Power, 1878-2007, Cambridge, Cambridge U.P., 2008, c. 5.

3 Madureira, Nuno Luis, "When the South Emulates the North: Energy Policies and Nationalism in the Twentieth Century», Contemporary European History, 17 (2008), págs. 1-21. El New Deal, en EE. UU., promovió asimismo la participación pública en la construcción de embalses mediante organismos autónomos, encargados de la gestión directa de los proyectos. Una visión renovada de la política de Roosevelt sobre el sector eléctrico en EMMONS, William M., «Franklin D. Roosevelt, Electric utilities and the Power of Competition», Journal of Economic History, 53, 4 (1993), págs. 880-907. Las realizaciones, en Billington, David P. y JACKSON, Donald C., Big Dams of the New Deal Era: a Confluence of Engineering and Politics, Norman, University of Oklahoma Press, 2006.

${ }^{4}$ Para Noruega, THÜE, Lars, «The State and the dual Structure of the Power Supply Industry in Norway, 1890-1940», en TRÉDÉ, Monique, Electricité et electrification, págs. 227-234; THÜE, Lars, «Electricity rules: The Formation and Development of the Nordic Electricity Regimes», en KAIJSER, Arne y Hedin, Marika (ed.), Nordic Energy Systems: Historical Perspectives and Current Issues, Canton, Massachusetts, Science History Publications, 1995, pág. 22. Para Suecia, JAKOBsson, Eva, «Industrialised Rivers. The development of Swedish Hydropower», en KAIJSER y HEDIN, Nordic Energy Systems, págs. 55-74. Finlandia, en MYLlYNTAUs, Timo, Electrifying Finland. The transfer of a New Technology into a late Industrialising Economy, Londres, Series A/ETLA- The Research Institute of the Finnish Economy, 1991. En Suiza, fue la iniciativa privada la que afrontó el cambio de escala desde la Ley Federal de 1916. PAQUIER, Serge, «Les caractères originaux des étapes de l'électrification suisse de 1880 à 1930, en TREDE, Monique, Électricité et électrification, pág. 211. No ha de olvidarse la importancia de las corporaciones locales en Canadá para la promoción hidroeléctrica, ARMSTRONG, Christopher y Nelles, H. Viv, Monopoly's Moment. The organization and Regulation of Canadian Utilities, 1830-1930, Toronto, University of Toronto Press, 1986. 
manos privadas hasta la posguerra mundial, pero, desde 1919, los auxilios públicos prestados a la construcción de presas y embalses contribuyeron significativamente al necesario aumento de la escala de la producción hidroeléctrica tanto en la Francia hidráulica, la del sudoeste, como en Italia. Estas ayudas se acompañaron de otras medidas para facilitar la financiación de las obras - como la garantía de los préstamos internacionales_-, así como de disposiciones para asegurar su rentabilidad a través de consumidores institucionales —ferrocarril e industrias químicas-5.

España formaba parte del grupo de los países hidroeléctricos de la Europa del Sur, pero se incorporó aún más tardíamente que Italia o Francia a su explotación en tanto que la ventaja relativa que representaba el uso energético del agua respecto al carbón no se presentó con claridad hasta que se sufrió la escasez de combustibles durante la Gran Guerra. Desde entonces y hasta los años sesenta se extiende la hegemonía del agua como fuente de la energía eléctrica en España. Hasta la guerra civil, de hecho, en el agua tenía su origen más del 90 por 100 de la electricidad producida y una cuarta parte del total de la energía consumida en el país ${ }^{6}$. Fue pues a partir del decenio de 1920 cuando se planteó por vez primera la posibilidad de una intervención del Estado para el fomento de la interconexión de líneas y la construcción de infraestructuras de almacenamiento hidráulico.

Así, la vertebración del mercado eléctrico a iniciativa pública contó con proyectos interesantes, que perseguían la interconexión entre los principales sistemas productivos y los grandes mercados de consumo, pero la llamada Red Eléctrica Nacional no se llevó a término ${ }^{7}$. El Estado tampoco emprendió por sí mismo la construcción de presas y embalses para uso eléctrico, pero sí subvencionó con ayudas extraordinarias la construcción de diques y vasos de almacenamiento hidráulico en dos momentos bien distintos: por la Ley Gasset de 7 de julio de 1911 y por el otorgamiento de subvenciones directas a algunas empresas para la construcción de embalses durante la dictadura Primorriverista. La

5 Levy-Leboyer, Maurice, «Panorama de l'électrification. De la grande guerre à la nationalisation", en LEVY-LEBOYER y MORSEL, L'interconnexion et le Marché 1919-1946, (Histoire Générale de l'électricité in France), t. 2, París, Fayard, 1994, pág. 13. OTTOLINO, Maria, "L'evoluzione legislativa», en RoSA, Luigi de (ed.), Il potenziamento tecnico e finanziario 1914-1925, t. 2, en Storia dell industria elettrica in Italia, Roma, Laterza, 1993, vol. 2, págs. 465-509. La importancia durante los últimos veinte del aval del Estado en los préstamos transnacionales, en STORACI, Marina y TATTARA, Giuseppe, «The external financing of Italian electric companies in the interwar years», European Review of Economic History (1998), 2, págs. 345-375.

6 SUDRIÀ, Carles, «Un factor determinante: la energía», en NADAL, CARrERAS y SUDRIÀ, (comp.), La economía española en el siglo XX. Una perspectiva bistórica, Barcelona, Ariel, 1987, pág. 324. BARTOLOMÉ, Isabel, «La industria eléctrica española antes de la guerra civil: reconstrucción cuantitativa», Revista de Historia Industrial, 15 (1999), pág. 155.

7 BARTOLOMÉ, Isabel, «La red nacional y la integración de los mercados eléctricos españoles durante los años de entreguerras. ¿Otra oportunidad perdida?», Revista de Historia Económica, 2 (2005), págs. 270-298. 
literatura jurídica especializada supone que los grandes beneficiarios del sistema subvencional que estableció la Ley Gasset fueron las explotaciones hidroeléctricas, pero no ofrece evidencia que justifique la afirmación ${ }^{8}$. Sintés y Vidal, los grandes publicistas del sector eléctrico español en los primeros treinta, también expresaron su queja por la discrecionalidad de las ayudas públicas a la construcción de diques durante la Dictadura, mientras que, paradójicamente, los representantes de las empresas eléctricas se enorgullecían de lo contrario9. Pese al potencial uso múltiple de esos vasos hidráulicos y a la declaración del suministro eléctrico como servicio público en 1924, las compañías presumían de haber acometido por sí solas, sin apoyo de la Administración, inversiones colosales en activos fijos e irrecuperables para otras actividades, como eran las presas y los embalses de almacenamiento de agua, llamando la atención sobre la singularidad del caso español en perspectiva europea ${ }^{10}$.

El análisis de contenido del discurso hidráulico español constituye un clásico de nuestra historiografía al que, últimamente, se han añadido trabajos sobre las realizaciones de la política hidráulica en algunas cuencas ${ }^{11}$. Nuestro conocimiento sobre los antecedentes de la industria eléctrica y sobre la dotación de infraestructuras de la economía española ha progresado también significativamente en los últimos años ${ }^{12}$. No obstante, a día de hoy, desconocemos por completo el alcance de las ayudas para la construcción de presas y vasos de

8 «...cuya rentabilidad económica a corto plazo atraía al capital extranjero». FANLO, Antonio, Las confederaciones hidrográficas y otras administraciones hidráulicas, Madrid, Civitas, 1996, pág. 85.

9 No obstante, Sintés y Vidal califican esta acción estatal de tímida e ineficaz y señalan la indiferencia, el abandono y el desamparo al que se sometió a esta industria. SINTES, Franciso F. y VIDAL, Francisco, La industria eléctrica en España, Barcelona, Montaner y Simón, 1933, pág. 489 y págs. 493-531.

${ }^{10}$ Decía por ejemplo Sánchez Cuervo: «Los únicos beneficios recibidos por esta industria han sido las concesiones gratuitas y a perpetuidad de aguas por el Estado». SANCHEZ CuERVO, Luís, «La situación actual de la industria española de producción y distribución de energía eléctrica», $L a$ Electricidad, (abril 1933), 172, pág. 7.

${ }_{11}$ Entre los clásicos, merecen una espacial atención ORTEGA, Nicolás, «El plan nacional de obras hidráulicas», en GIL OlCiNA, Antonio y MORAles GIL, Alfredo (coord.), Hitos históricos de los regadíos españoles, , Madrid, Ministerio de Agricultura, Pesca y Alimentación, 1992, págs. 309-334. Y ORTEGA, Nicolás, «La política hidráulica española hasta 1936», en GARRABOU, Ramón y NAREdo, José María (eds.), El agua en los sistemas agrarios. Una perspectiva histórica. Madrid, Visor, 1999, págs. 159-180; y GómEZ MENDOZA, Josefina, «Regeneracionismo y regadíos», en GIL OlCina y Morales Gil, Hitos históricos de los regadíos, págs. 336-363. Y Fernández Clemente, Eloy, Un siglo de obras hidráulicas en España. De la utopía de J. Costa a la intervención del Estado, Zaragoza, Universidad de Zaragoza, 2000. Las realizaciones, en BARCiEla, Carlos y Melgarejo, Joaquín, El agua en la historia de España, Alicante, Universidad de Alicante, 2000. Y, en particular, PInILla, Vicente (ed.), Gestión y usos del agua en la cuenca del Ebro en el siglo XX, Zaragoza, Prensas Universitarias de Zaragoza, 2008.

12 Herranz, Alfonso, La dotación de infraestructuras en España, (1844-1935), Madrid, Banco de España, 2004. BARTOLOMÉ, Isabel, La industria eléctrica en España, 1890-1936, Madrid, Banco de España, 2008. 
almacenamiento que recibió el sector eléctrico hasta la guerra civil, tanto por efecto de la Ley Gasset como durante la Dictadura y recuérdese que este período coincide con el de mayor dependencia del sector eléctrico español del uso del agua. Así pues, para procurar su esclarecimiento, las tres primeras secciones de este artículo se dedican a explicar la oportunidad y finalidad de dichos auxilios y las dos siguientes a examinar sus realizaciones. Ahí se siguen tanto un procedimiento directo como otro indirecto para desglosar cuáles fueron efectivamente las ayudas recibidas por las empresas hidroeléctricas ${ }^{13}$. Aquí se sostiene que los empresarios estaban en lo cierto y que el escándalo, cuando lo hubo, se suscitó más por la discrecionalidad en el procedimiento de concesión de las ayudas que por su volumen.

\section{LAS POlÍticas DE FOMENTO HIDRÁUlico. PRESAS COSTOSAS Y POLIVALENTES}

Las políticas públicas que afectan a las corrientes de agua se clasifican en dos grupos: aquellas que asignan sus usos y usuarios y que, por tanto, regulan el acceso a este bien público a través de los llamados regímenes concesionales; y aquellas intervenciones de la Administración que procuran aumentar, o disminuir, la disponibilidad de agua mediante la construcción de infraestructuras de distribución — por canales - , de almacenamiento — mediante embalse-y de transporte -en los trasvases-. Considerados globalmente, durante los dos últimos siglos, se han alternado fases de predominio constructor, tanto de canales como de diques de defensa y contención; con otras, en que el quehacer de las administraciones se ha centrado en la asignación de los recursos. Así, mientras que en el cambio del siglo XVIII al XIX la iniciativa fue pública, en buena parte de ese siglo y los primeros decenios del siglo XX la construcción de infraestructuras hidráulicas se abandonó a manos privadas. Durante la segunda mitad del siglo XX, en cambio, se esperó de la Administración un incremento continuado de la disponibilidad de agua mediante la regulación de las corrientes y luego los trasvases. Esta doctrina del Estado como provisor de infraestructuras hidráulicas se abrió paso siguiendo un itinerario no exento de dificultades.

${ }^{13}$ La cuantía de los auxilios públicos efectivamente cobrados por las compañías eléctricas se podría averiguar de dos maneras, comprobando las libranzas del pagador o confirmando los cobros de los auxiliados. Lamentablemente, la información custodiada en el Ministerio de Hacienda no permite un seguimiento tan pormenorizado de las ayudas, que aparecen en los presupuestos generales bajo epígrafes correspondientes al conjunto de las obras hidráulicas. En el mejor de los casos, distinguiendo entre aquellas de iniciativa pública y aquellas de promoción particular. Tampoco ha sido fácil corroborar el monto de las ayudas desde el lado de las compañías, dada la dispersión y la dificultad en el acceso a los archivos de las compañías eléctricas españolas. Esto nos ha obligado a un procedimiento indirecto para examinar las ayudas eléctricas correspondientes a la Ley Gasset. Para los montos pendientes de los pagos prometidos durante la Dictadura, hemos contado con información compilada en el Archivo del Banco de España. 
Las ayudas ocasionales se fueron sustituyendo por la ordenación y la planificación hidrológica sistemática, aprovechando los períodos bélicos, cuando acuciaba una dotación regular y creciente tanto de agua como de energía ${ }^{14}$.

La difusión de la generación hidroeléctrica a gran escala en la posguerra europea contribuyó sustancialmente a este cambio apreciable de las políticas hidráulicas. En los territorios mejor dotados para el aprovechamiento hidroeléctrico, como en la Europa Nórdica, la energía cinética obtenida por efecto del caudal y la caída del salto se había empezado a explotar en los últimos años del siglo XIX a fin de obtener electricidad. El agua se aprovechaba bien directamente o bien aumentado su pendiente, mediante la derivación por canales de los flujos procedentes de acumulaciones naturales en los cursos altos de los ríos $^{15}$. Este modelo se emuló en los países deficitarios de energías fósiles, pero que contaban con una dotación hidrográfica menos generosa ${ }^{16}$. En la Europa del Sur —el sudeste francés, Italia o la Península Ibérica_-, la volatilidad estacional de los caudales, exceptuando las escasas localizaciones favorecidas con un régimen nival, forzaba el empleo de centrales térmicas de reserva para cubrir los meses de sequía. Esto imponía elevados costes unitarios: la potencia térmica se mantenía inutilizada por períodos prolongados y cuando se usaba redundaba en costes de explotación elevados, debido al precio del combustible ${ }^{17}$. En los países donde el agua devengaba únicamente una ventaja relativa, un trasvase energético entre los meses de abundancia y aquellos de sequía permitiría prescindir de estas reservas y, por tanto, rebajar los costes de explotación unitarios. Ese trasvase solo se procuraría mediante el almacenamiento de agua, en embalses de acumulación estacional a partir de 1910 y anual e interanual a partir de 1925 . Estos vasos iban dotados de presas y aliviaderos, que consentían el cerramiento del cauce, además de la obra hidráulica propiamente eléctrica —canales de derivación, chimeneas, tuberías forzadas y casas de máquinas- ${ }^{18}$.

${ }^{14}$ Los elementos básicos de la economía de los recursos naturales, en general, y del agua en España, en particular, en Young, Robert. A. y HAVEMAN, Robert. H., «Economics of Water Resources: a Survey», en KNEESE, Allen V. y SwEENY, James L., Handbook of Natural Resource and Energy Economics, vol. II, c. 5, Elsevier, North Holland, 1985, págs. 465-530; AGUILERA, Federico (ed.), Economía del agua, Madrid, Guadarrama, 1992; y NAREDO, José M., La economía del agua en España, Madrid, Visor, 1997. En la última crisis finisecular, se ha reanudado el debate de la asignación.

15 Véase KAIJSER Y Hedin, Nordic Energy Systems: Historical.

16 Madureira, Nuno L., «When the South Emulates», págs. 1-21.

17 Por aquel entonces, los sistemas eléctricos de interconexión eran aún primitivos y los mercados regionales de electricidad progresaban con lentitud, exceptuando Suiza, Suecia y Francia. Para Escandinavia, KAIJSER, Arne, «Controlling the grid. The development of high-tension power lines in the Northern countries», en KAIJSER y HEDIN, Nordic Energy Systems: Historical, págs. 31-54; Italia, en GiANNETTI, Renato: «Tecnologie di rete e intervento pubblico nel sistema elettrico italiano (1883-1996)», Storia Economica, (agosto 1997), págs. 127-160.

${ }_{18}$ La técnica hidráulica en Gómez Navarro, José Luís: Saltos de agua y presas de embalse, 2 v., Madrid, Publicaciones de la Escuela Especial de Ingenieros de Caminos, Canales y Puertos, 1932. 
En 1909, la técnica había resuelto la mayoría de los problemas teóricos básicos de la edificación de grandes presas, pero la práctica constructiva avanzaba con lentitud, al tiempo que la difusión del hormigón y la planta curvilínea de los diques. Solo al final del decenio de 1920 se acometió en Europa la construcción de los primeros hiperembalses para la regulación integral de las corrientes $^{19}$. En vías de superar el reto técnico, se presentaron otros de orden financiero e institucional.

El desafío financiero que imponía la construcción de estas infraestructuras hidráulicas fue para sus promotores una empresa de dimensión semejante al tendido de las redes ferroviarias en el siglo anterior. Se precisaba una capitalización colosal, para invertir en unos activos irrecuperables para otras actividades. Pero, a diferencia del ferrocarril, la inversión era desembolsable en un breve período y además creciente, como la dimensión de las infraestructuras. Por ejemplo, el salto de Bolarque y la traída de fluido a Madrid costaron a los promotores de la Unión Eléctrica Madrileña alrededor de 19 millones de Pta. de 1910; en los primeros treinta, los Saltos del Duero, que constaban de una gran presa sobre el Esla, alcanzaron los 145 millones de $1933^{20}$. Las redes de transporte y distribución se agregaban acumulativamente, como los equipos hidráulicos y eléctricos en los grupos de generación; sin embargo, la obra civil, las infraestructuras, se dimensionaban de una vez. Y estas comportaban en torno a un 23 por 100 del total del capital invertido en los sistemas hidroeléctricos ya terminados y un 50 por 100 cuando se excluía la distribución ${ }^{21}$. Así, en España, el sector eléctrico se convirtió en el principal destino de toda la inversión durante el primer tercio del siglo XX, superando a los ferrocarriles en el decenio de 1920. La iniciativa foránea había sido decisiva para la difusión inicial de la tecnología electrotécnica, pero desde el comienzo del siglo XX la banca industrial española fue quien asumió su financiación ${ }^{22}$.

19 Recuérdese que la emblemática presa Hoover, inicialmente Boulder, sobre el río Colorado, se inauguró en 1935. La difusión de la hidroelectricidad en California, en HugHEs, Thomas P., Networks of Power: Electrification in Western society, 1880-1930, Baltimore, The Johns Hopkins University Press, 1983 , c. X.

20 20,5 y 91,5 millones respectivamente en pta. constante de 1913. Escritura de Constitución de la UEM, 10/02/1912, Base cuarta, aportación de los Sres. Urquijo y Ron, Archivo-UEM, Madrid. Saltos del Duero, información procedente de DíAZ MORLÁN, Pablo, «El proceso de creación de Saltos del Duero (1917-1935)», Revista de Historia Industrial, 13 (1998), págs. 181-198. Índice de precios de PRADOS DE LA Escosura, Leandro, El progreso económico de España, Bilbao, Fundación BBVA, 2003.

${ }^{21}$ Los cálculos de la inversión de preguerra, en BECERRIL, Enrique, «El proceso de amortización de la industria eléctrica española», Moneda y crédito, 18 (1946), págs. 36-44. Son los que emplea HERRANZ, Alfonso, La dotación de infraestructuras en España.

22 Véase Segreto, Luciano, «Imprenditori e finanzieri», en Giorgio MORI, Storia dellindustria elettrica in Italia. I. Gli origini. 1882-1914, vol. II, Roma, Laterza, 1992, págs. 249-331; y, para las estrategias de los conglomerados electro-técnicos, HERTNER, Peter, "Financial Strategies and Adaptation to Foreign Markets: the German Electrotechnical Industry and its Multinational Activities: 1890s to 1939», en Teichova, Alice, LÉvY-Leboyer, Maurice y Nussbaum, Helga (ed.), Multinational 
El segundo desafío era de orden institucional. Los vasos de almacenamiento de agua inundaban terrenos, alteraban usos consecutivos y, en general, competían con otros empleos tradicionales y alternativos del agua. Con la autorización para la construcción de embalses, se involucraba al conjunto de los usuarios de la cuenca y se impedían los usos hasta entonces prioritarios, la navegación y el transporte. Los nuevos regímenes concesionales que vieron la luz en la postguerra europea impusieron la regulación pública del procedimiento de acceso para evitar eventuales daños a terceros. Perseguían garantizar la transparencia en el procedimiento, además de reparar el daño a los propietarios de los terrenos inundados y a los usuarios afectados aguas arriba y aguas aba$\mathrm{jo}^{23}$. No obstante, una vez resuelta la libre concurrencia entre usuarios y establecidas las compensaciones a terceros, persistió la comprometida cuestión del orden de prelación entre los usos hidráulicos del vaso ${ }^{24}$.

Los embalses garantizaban el abastecimiento, el riego, prevenían de las avenidas y procuraban flujo continuo para los aprovechamientos hidroeléctricos, pero, aunque los tres primeros usos se consideraran desde antaño bienes públicos puros, la explotación hidroeléctrica era aún en 1920 un negocio estric-

Enterprise in Historical Perspective, Cambridge, Cambridge U.P., 1986. La comparación transatlántica, en Hausman, William J., Hertner, Peter y Wilkins, Mira, Global electrification. España, en NúÑEZ, Gregorio, «Empresas de producción y distribución de electricidad en España (1878-1953)», Revista de Historia Industrial, 7 (1995), págs. 199-227. Y en VALDALISO, Juan M., «Los orígenes de Hidroeléctrica Ibérica, Hidroeléctrica Española y Saltos del Duero», en ANES, Gonzalo, Un siglo de luz. Historia empresarial, págs. 97-129.

${ }_{23}$ Tradicionalmente, los regímenes de asignación de usos del agua del siglo XIX se clasificaban en dos grupos. Allí donde el lecho y el cauce del río eran de propiedad pública, aunque el uso pudiera ser privado; y aquellos regímenes en que las corrientes se consideraban de propiedad privada y, por tanto, sus usos no eran competencia de la Administración. La propiedad privada de los ríos predominaba en Escandinavia, hasta que a principios del XX, el propio Estado en Suecia, pero también en Noruega, compró aprovechamientos hidráulicos a fin de explotarlos por sí mismo o reservarlos para que lo hicieran los municipios. En contraste, en el Sur de Europa, las corrientes de agua eran recursos públicos, aunque su acceso estuviera restringido, dando preferencia a los ribereños en las zonas húmedas, como en Suiza o Francia, o bien por prescripción en las zonas áridas, como en Italia o España. Tanto los derechos de las comunidades de ribereños, como de los usuarios sujetos a prescripción, entraron en colisión con los nuevos usos hidroeléctricos y los Estados del Sur de Europa procedieron a elaborar nuevos sistemas de asignación, en la posguerra europea. Los sistemas nórdicos, en THÜE, Lars, «Electricity rules»; Suiza en PAQUIER, Serge, «Les caractères originaux des étapes de l'électrification suisse de 1880 à 1930», en TREDÉ, Monique, Électricité et électrification, págs. 203-212; Francia, en ÁlvarEZ BUYLLA, Vicente, Economía y legislación extranjera acerca de la energía hidroeléctrica, líneas y redes, Madrid, Gráficas Reunidas, 1932; Italia, en CiARLO, Pietro, «Il testo unico del 1933 sulle acque e sugli impianti elettrici», en GALASSO, Giuseppe, Storia dell'industria elettrica in Italia, 3*, Espansione e oligopolio, 1926-1945, Roma, Laterza, 1993.

${ }^{24}$ Los empleos tradicionales de las corrientes de agua son la navegación, el transporte por flotación, el agua de boca, los usos agrarios y los industriales. En la segunda mitad del siglo XX, a estos se añadieron los usos lúdicos y recreativos y las reservas para usos futuros. YOUNG y HAVEMAN, «Economics of Water Resources», pág. 506. 
tamente privado, cuyo carácter de servicio público no estaba siquiera reconocido por las administraciones de muchos países, entre ellos España ${ }^{25}$. Pese a no albergar un uso consuntivo, los vasos de almacenamiento hidroeléctrico impedían u obstaculizaban otros proyectos. Por ejemplo, sus diques se ubicaban allí donde las alturas fueran mayores, para obtener una caída superior con la derivación de los caudales; en contraste, los orientados al regadío se localizaban allí donde el terreno inundable fuera de menor calidad. En la práctica, la electricidad y riego se presentaban con frecuencia como usos incompatibles.

La doble vertiente financiera e institucional del reto que representaba la construcción de embalses a gran escala la expresaba Carlos Mendoza, responsable de Mengemor, en 1926 desde las páginas de la Revista de Obras Públicas, tratando de legitimar los auxilios concedidos a Canalización y Fuerzas del Guadalquivir26.

«Completado el estudio económico, se llegó fácilmente a la conclusión de lo dificilísimo que sería para nuestra Sociedad o para otra cualquiera abordar económicamente el asunto, si se mantenía el pensamiento capital que informaba el proyecto. Mas parecía natural que, derivándose para el Estado y los intereses generales tantas ventajas de diverso orden, alguna ayuda, en una u otra forma, pudiera merecer nuestra iniciativa» 27 .

Además de la subvención, demandaba los cambios en la Ley de Aguas que acabaran con la doctrina de la concesión rogada y facilitasen la agregación de permisos y su declaración de utilidad pública:

«(...) Bien se comprende que no era cosa fácil encajar todo esto dentro de una concesión ordinaria, con subvención o sin ella, no siendo nuestro propósito explotar la vía navegable [...],Sin embargo, era necesario llegar a un solución para que, al amparo de la ley y con toda tranquilidad, pudiera la empresa concesionaria realizar sus obras y desenvolver sus explotaciones. El caso era nuevo y la solución tendría que ser también forzosamente nueva».

${ }_{25}$ En algunos países, la distribución era pública y a cargo de los ayuntamientos. En España, por Decreto de 12 de abril de 1924, el suministro comercial de electricidad se reconoció como servicio público. García-Rodrigo, Carlos M., Legislación Eléctrica, Madrid, Revista de los Tribunales, 1927, pág. 250.

${ }^{26}$ La Compañía Anónima Mengemor fue creada en 1904 como gabinete de ingeniería por los ingenieros españoles Mendoza, González Echarte y Moreno, pero acabó convirtiéndose en la una empresa hidroeléctrica interesada en Madrid, Ohanes-Almería y Jaén. A este último proyecto, de regulación coordinada del Guadalquivir, es al que se refiere en el texto Carlos Mendoza. Un estudio de gran interés sobre la compleja actividad de Mengemor, en BERNAL, Antonio M., «Ingenierosempresarios en el desarrollo del sector eléctrico español: Mengemor, 1904-1951», Revista de Historia Industrial, 3 (1993), págs. 93-126.

27 Según el proyecto inicial, la compañía acometía los saltos (60 millones) y el Estado la navegabilidad del río (20 millones). MENDOZA, Carlos, «Canalización del Guadalquivir», ROP (1919), págs. 196-201; MENDOZA, Carlos, «Idea general del proyecto de canalización y fuerzas del Guadalquivir», ROP, 74 (1926), pág. 482. 
En las dos siguientes secciones se analizan sucesivamente ambos desafíos, financiero e institucional, que se presentaron durante el primer tercio del siglo $\mathrm{XX}$ al sector hidroeléctrico español. En otras palabras: el grado de dependencia del agua embalsada para el aprovechamiento eléctrico y los ejes de la "política hidráulica».

\section{VASOS DE ALMACENAMIENTO E HIDROELECTRICIDAD EN ESPAÑA}

En el territorio español, la explotación hidroeléctrica empezó en torno a 1890, con saltos que aprovechaban caídas de agua, con pequeñas represas, o que la derivaban mediante canales. En su mayoría, eran localizaciones donde se explotaba desde antiguo la energía hidromecánica. En la España húmeda, su adopción fue rápida, pero también en otros territorios del interior peninsular, donde los molinos y aserraderos cedieron una parte de su energía sobrante para la iluminación de los núcleos cercanos ${ }^{28}$. En 1901, y según la estadística pública, se contaban más de 500 establecimientos hidroeléctricos en España ${ }^{29}$. A partir de 1901, con la fundación de Hidroeléctrica Ibérica en el País Vasco y la constitución del resto de las grandes hidroeléctricas - la Española en 1907 a fin de servir a Madrid y Valencia, Unión Eléctrica Madrileña en 1910, la Barcelona Traction en 1911, etcétera-, se procedió al aprovechamiento sistemático de los saltos disponibles al hilo de agua. Las cuencas cantábricas, pirenaicas y de la Cordillera Ibérica fueron escrutadas a fin de localizar lagunas de almacenamiento natural y alturas suficientes para emplear, mediante derivación, sus flujos discontinuos. Estas cuencas se localizaban a una distancia media de los centros de consumo que no excedía los $300 \mathrm{~km}$, lo que hacía viable el transporte de fluido a través de líneas de alta tensión ${ }^{30}$.

Ahora bien, una vez utilizados los saltos que aprovechaban la acumulación en lagunas naturales, los grandes diques comenzaron a resultar imprescindibles tanto para aminorar el recurso a las reservas térmicas como para incrementar los rendimientos a escala de la generación hidroeléctrica ${ }^{31}$. Desde 1910, el grueso de los saltos incorporados a la explotación hidroeléctrica en España era mayor de $5.000 \mathrm{~kW}$ (Véase cuadro 1) y, a partir de 1925, mayor de 15.000,

\footnotetext{
${ }^{28}$ GARRUÉs, Josean, «Electricidad e industria en la España rural: el Iratí, 1904-1961», Revista de Historia Económica, 1 (2006), págs. 97-138.

${ }^{29} \mathrm{La}$ potencia instalada total en establecimientos hidroeléctricos era de $32.135,81 \mathrm{~kW}$ en 541 saltos, cuya potencia media era de 59,40 kW. Elaboración propia a partir de DIRECCIÓN GENERAL DE AGRicultura, INDUSTRIA y COMERCiO, Estadística de la Industria Eléctrica en España a fin de 1901, Madrid, Imprenta de los Hermanos de Manuel G. Hernández, 1901.

${ }^{30}$ Dos ejemplos de la explotación hidroeléctrica en España, en SÀnCHEZ VILANOVA, Llorenç, L'aventura hidroelèctrica de la Vall de Capdella, Barcelona, FECSA, 1992; y CHAPA, Álvaro, Cien años de historia de Iberdrola. Los hechos, vol. 2, Madrid, Iberdrola, 2002.

${ }^{31}$ Así lo expresaba el impulsor de las empresas eléctricas del Grupo Vizcaya. URRUTIA, Juan, La energía hidroeléctrica de España. Antecedentes que deben tenerse en cuenta, Madrid, Sociedad Española de Artes Gráficas, 1918.
} 
en su mayoría dotados de embalse. De hecho, la regulación del caudal era necesaria para la explotación de un 38,34 por 100 del potencial hidroeléctrico español. En las cuencas del Tajo y Duero, este porcentaje superaba el 50 por 100 y en la vertiente del Guadalquivir alcanzaba casi el 100 por $100^{32}$. La dependencia del parque hidroeléctrico español del aumento de la capacidad de regulación anual no era proporcional al tamaño de su sector hidroeléctrico. En vísperas de la II Guerra Mundial, Italia, territorio de mayor éxito hidroeléctrico, se auxiliaba con caudales regulados en un menor porcentaje que España. Una buena parte de los saltos italianos explotaba caudales de régimen nival alpino, mientras que el régimen pluvial mediterráneo predominaba en España, con caudales volátiles, tanto estacional como anualmente ${ }^{33}$.

CUAdro 1. GRUPOS ELÉCTRICOS INCORPORADOS EN ESPAÑA SEGÚN SU TAMAÑO. (LA POTENCIA EN KW)

\begin{tabular}{|c|c|c|c|}
\hline Año & \multicolumn{2}{|c|}{$\begin{array}{c}\text { Porcentaje de la potencia incorporada se- } \\
\text { gún el tamaño de los grupos generadores }\end{array}$} & $\begin{array}{c}\text { Potencia real in- } \\
\text { corporada en } \mathrm{kW}\end{array}$ \\
\hline Potencia & $<5.000 \mathrm{~kW}$ & $>5.000 \mathrm{~kW}$ & \\
\hline$<1900$ & 100,00 & 0,00 & $25.222,4$ \\
\hline $1901-5$ & 86,57 & 13,43 & $41.233,6$ \\
\hline $1906-10$ & 100,00 & 0,00 & $34.481,6$ \\
\hline $1911-15$ & 27,26 & 72,74 & $139.153,6$ \\
\hline $1916-20$ & 31,85 & 68,15 & $142.469,6$ \\
\hline $1921-25$ & 34,91 & 65,09 & $203.688,8$ \\
\hline $1926-30$ & 21,53 & 78,47 & $230.384,8$ \\
\hline $1931-35$ & 7,85 & 92,15 & $330.436,8$ \\
\hline
\end{tabular}

FuENTE: Elaboración propia a partir de SindicAto NACiONAL DE AgUA, GAS y Electricidad, Datos estadístico-técnicos de las centrales. La fuente se discute en BARTOLOMÉ, I., «La industria eléctrica española antes de la guerra».

Tras la guerra civil, el aumento de la explotación hidroeléctrica dependió aún más del embalse de agua. El total de la capacidad de los vasos españoles,

32 UNESA, Estimación del potencial bidroeléctrico en España, Madrid, Aldus, 1957, pág. 49.

33 Cuando la industria hidroeléctrica española dio alcance a la italiana de 1935, y logró en 1958 casi cuatro millones de kW instalados, un 75 por 100 se obtenía en centrales mayores de $15.000 \mathrm{~kW}$, mientras que en la Italia de 1935 apenas sobrepasaba el 60 por 100. Los datos españoles proceden de una elaboración propia a partir de SindiCATO NACiONAL DE AGUA, GAS Y ElECTRICIDAD, Datos estadístico-técnicos de las centrales eléctricas españolas en 1958, Madrid, Servicio Sindical de Estadística, 1960. Para Italia, GiUnTINI, Andrea, «Fonti statistiche», en GALASSO, Giuseppe, Storia dell'industria elettrica in Italia, 3*, Espansione e oligopolio, 1926-1945, Roma, Laterza, 1993 , pág. 1173. 
incluidos aquellos destinados exclusivamente al riego o al abastecimiento de agua para el consumo, se sextuplicó en treinta años y la potencia hidroeléctrica creció a un ritmo muy similar al del almacenamiento de agua ${ }^{34}$.

El recurso a la acumulación de agua para producir electricidad contribuía eficazmente a la disminución de los costes de explotación de las empresas hidroeléctricas, pero aumentaba significativamente los costes de instalación de las centrales de generación. En España y en 1917, el promedio de los recursos básicos invertidos por $\mathrm{kW}$ de potencia instalada sobrepasaba ligeramente las 970 Pta., en peseta constante de 1913. En 1930, tras la inauguración de algunos embalses importantes, este excedía las 1.900 Pta. de 1913. En 1935, con la explotación de algunos grupos en Saltos del Duero, el kW instalado acumulaba un coste de $2.449 \mathrm{Pta}^{35}$. Lo abultado y abrupto de la inversión se compadecía mal con el crecimiento lento de la demanda eléctrica española, aferrada a los usos discontinuos - manufactura y alumbrado- con picos elevados de carga, pero que mantenía bajos rendimientos. Por lo demás, la especificidad de los activos eléctricos - su inamovilidad e irrecuperabilidad para otras actividades-, tampoco facilitaba la búsqueda de inversores. Las empresas eléctricas emplearon recursos propios, ajenos y el endeudamiento bancario, pero, pese a la fortaleza de los títulos de las mayores, las inversiones en obra civil se aplazaban incluso entre ésas hasta que la demanda estaba asegurada. Francesca Antolín ha demostrado que Hidroeléctrica Ibérica pospuso las inversiones pirenaicas, en el Cinca, durante el decenio de 1920, por esta razón. Ese temor al exceso de producción explica también el período de calma constructiva en otros embalses de gran envergadura, planeados en torno a la I Guerra Mundial pero construidos a partir de 1925 e inaugurados en los primeros treinta, - Millares por parte de HE, Saltos del Duero en el Esla y los saltos escalonados del Guadalquivir-.

En Italia y Francia, a fin de compensar la rigideces de sus respectivas ofertas hidroeléctricas, el Estado subvencionó diques y vasos de acumulación. En Italia, la conquista della forza constituyó uno de los lemas básicos de la era Mussoliniana ${ }^{36}$. Se subvencionaba la maquinaria instalada y el agua embalsada desde 1919, pero el régimen fascista alteró el régimen de subvenciones para la

${ }_{34}$ DíAZ-MarTa, Manuel L., Las obras hidráulicas en España, Aranjuez, Doce Calles, 1969 (reed. 1997), pág. 72.

35 Recursos básicos son la suma de los valores del capital social, acciones desembolsadas y obligaciones en circulación. Elaboración propia a partir de Anuario Financiero y de Sociedades Anónimas de España, en las respectivas fechas y, para la potencia instalada, BARTOLOMÉ, Isabel, «La industria eléctrica española antes de la guerra». Las fuentes, en BARTOLOMÉ, Isabel, La industria eléctrica en España. Anejo 3.

36 Consistió en favorecer un incremento abultado de la capacidad, incluido el árido Sur de la Península. El lema corresponde a Nitti, quien así tituló su opúsculo de 1905 sobre el rescate de las fuerzas hidráulicas italianas. OTTOLINO, Maria, «L'evoluzione legislativa», pág. 470 y BARONE Giuseppe, "Nitti e il dibattito sull'energia», en RosA, Luigi de, Il potenziamento tecnico e finanziario, pág. 201. 
construcción de nuevas presas en interés de los industriales, sufragándose entonces el coste de la obra ${ }^{37}$. En Francia, la política hidráulica se insertó en un proyecto más general de reforzamiento energético, que incluyó la interconexión entre sistemas eléctricos complementarios — sudeste hidroeléctrico y noroeste térmico-y la promoción de industrias de consumo intensivo de electricidad $^{38}$. La Ley de 1919 ofreció subvenciones a las infraestructuras eléctricas, de modo que, hasta 1930, se subvencionó con más de 60 millones de Francos, con un efecto indudable en el crecimiento del parque hidroeléctrico francés ${ }^{39}$.

\section{LA NUEVA «POLÍTICA HIDRÁULICA» Y LOS EMBALSES PARA USOS MÚLTIPLES}

La dotación de agua en la España seca no es solo escasa, sino muy volátil. Sus reservas han sido siempre muy apreciadas, en tanto el rendimiento agrícola se ha pensado proporcional a la disponibilidad de agua para riego ${ }^{40}$. Más aún desde que el «Costismo», en el ambiente propicio de la Crisis finisecular del XIX, proclamara la «Guerra interior» contra la sequía. La desigual distribución de las lluvias — territorial y estacionalmente-, junto a la mala disposición del relieve, pasaron a argüirse como los principales males a atajar. Relieve y pluviosidad se relacionaban con otro factor preocupante, la torrencialidad de los ríos, que ocasionaba un verdadero «mal de la piedra» por la violencia e importancia de los arrastres y era causante de la erosión de los suelos. Su corrección pasaba por rectificar la asimetría con que se distribuía naturalmente el agua en España. A juicio de los regeneracionistas, se trataba de crear en el país una red hidráulica, compuesta de embalses y canales, que evacuasen esas aguas en las zonas áridas del territorio ${ }^{41}$. Estos postulados se institucionalizaron a partir de

37 CiARlo, Pietro, «Il testo unico del 1933 sulle acque», pág. 84.

38 Un plan semejante se acometió 20 años después en Portugal. Esta vez por iniciativa pública y capital preferentemente privado. Madureira, Nuno Luís, A História da Energia. Portugal 18901980, Lisboa, Livros Horizonte, 2005.

39 Según las informaciones sobre presupuestos y saldos del Estado francés extractados en la Revue Générale de la Électricité en SuElTo, Sin Título (1929), pág. 118 y SuELTO, Sin título (1931), págs. 75 y 76.

${ }^{40}$ En palabras de FANLO: «...en España, por sus condiciones hidrológicas, sin obras (en especial las de regulación) no hay agua; o no la hay con la seguridad física y jurídica, necesaria, dada la irregularidad espacial y temporal del sistema de precipitaciones». FANLO Antonio, «El marco jurídico de la creación y actuación posterior de las confederaciones hidrográficas en España», en Pinilla, Vicente, Gestión y usos del agua en la cuenca del Ebro, pág. 102.

${ }^{41}$ El Cuerpo de Ingenieros de Montes abogaba, sin embargo, por concentrar los esfuerzos en la repoblación forestal, que procurase una corrección hidrográfica a largo plazo. Estos postulados nutrieron el programa del Partido Conservador, pero sus realizaciones prácticas fueron escasas, respaldando luego el partido las posiciones en pro de la construcción civil de Gasset. Un excelente resumen de estos enunciados en ORTEGA Nicolás, «El plan nacional» y ORTEGA Nicolás, «La política hidráulica», pág. 160; y GómEZ MENDOZA, Josefina, «Regeneracionismo y regadíos», pág. 240. 
1898 — desde el Cuerpo de Ingenieros de Caminos, las diferentes Cámaras y la propia opinión pública - divulgándose la llamada «nueva política hidráulica» ${ }^{42}$.

Durante la segunda mitad del siglo XIX, el eje básico de la intervención pública de fomento hidráulico fue favorecer el regadío, pero respetando el principio de subsidiariedad. Este nutrió la legislación de la Restauración española desde la Ley de Aguas de 1879. Los particulares eran los encargados de promover y sufragar sus iniciativas, aunque la Ley Gamazo de 1883 previese que el Estado contribuyese con una parte de la obra civil. Los canales eran por entonces las infraestructuras hidráulicas que atraían las inversiones: la distribución de agua al mayor número de predios se entendía universalmente válida y fructífera en territorio español.

La Ley de Aguas de 1879 se forjó en un tiempo en que, aparte de la navegación y la flotación, apenas se concebían otras utilizaciones de las corrientes que no fueran el agua de «boca» y la agrícola. Según su artículo 160, en el orden de prelación de los empleos del agua, los usos industriales eran relegados al quinto lugar ${ }^{43}$. En el momento de su promulgación, estos únicamente eran los tradicionales de la hidromecánica - molinería y aserraderos- Ubicados en las orillas de los ríos, apenas alteraban el curso de las corrientes y no eran consuntivos.

Con el nuevo siglo, la nueva política hidráulica de la Restauración, que encarnaron los sucesivos Ministerios de Agricultura y luego Fomento de Rafael Gasset, mejoró el conocimiento del terreno y de la hidrografía peninsular, distinguiéndose entre unidades geográficas diferenciadas, con necesidades hidráulicas e, incluso, perspectivas diversificadas de crecimiento agrario. Durante los sucesivamente interrumpidos Ministerios de Gasset, entre 1900 y 1923, se crearon organismos de coordinación hidrográfica, aparte de las 7 divisiones hidráulicas iniciales, que se encargarían de la recogida de datos para la confección del apresurado Plan de 1902, que señalaba la construcción de 222 pantanos $^{44}$. Gasset abogó por una mayor intervención de la Administración como planificadora de una política centrada en las construcciones en el momento en que la prioridad hidráulica cambió de la canalización al embalse ${ }^{45}$. No obstante, la realización de su Plan avanzó con lentitud, principalmente por lo magro

42 Un pormenorizado análisis de los postulados de la «Nueva Política Hidráulica», Villanueva, Gregoria, La «política hidráulica» durante la Restauración (1874-1923), Madrid, UNED, 1991, pág. 96. Una lectura reciente en RAMOS, José Luís, «La formulación de la política hidrológica en el siglo XX: ideas e intereses, actores y procesos políticos», Ekonomiaz, 2001, págs. 126-151.

${ }^{43}$ Sigo el repertorio de La Iglesia Gustavo, Legislación de Aguas de la Revista de los Tribunales, (7 ${ }^{\mathrm{a}}$ ed.), Madrid, Revista de los Tribunales, 1928, pág. 255.

${ }^{44}$ En 12 de abril de 1901 se había creado el Registro de Aprovechamientos de Aguas Públicas en la Dirección de Obras Públicas y en las correspondientes Jefaturas Provinciales.

45 El cuerpo de Ingenieros de Caminos en 1899 comenzó a considerar los embalses no solo alimentadores, sino también como reguladores de caudales y, por tanto, susceptibles de uso polivalente y, por tanto, de intervención pública. Villanueva, Gregoria, La «política hidráulica» durante la Restauración, pág. 159. 
del presupuesto. Esta circunstancia se trató de atajar con la Ley de Grandes Regadíos o Ley Gasset, de 7 de julio de 1911, de auxilio a la inversión hidráulica ${ }^{46}$.

El Plan Gasset de 1902 había incluido una exhaustiva relación de obras hidráulicas aconsejables. La Ley Gasset de 1911 estableció que el proyecto y la construcción hidráulica correspondían al gobierno, aunque se preveían tres procedimientos con diverso grado de colaboración con la iniciativa privada, representada por las asociaciones de regantes ${ }^{47}$. Durante las sucesivas entradas de Gasset en el Ministerio (1913, 1916 y 1923) se persiguió la ejecución del Plan de 1902 y de la Ley de 1911, a través de los Planes extraordinarios de Obras Públicas, como el de 1916. Incluso el Partido Conservador hizo suyos algunos de estos enunciados mediante el Plan de Obras Hidráulicas de 1919 y el Proyecto de Reconstrucción Nacional de La Cierva. Durante sus años de vigencia, hasta 1926, sin embargo, no se otorgaron los presupuestos extraordinarios previstos y, en buena medida, el proyecto murió por consunción ${ }^{48}$.

La perspectiva marcadamente agraria de la Gran Política Hidráulica empezó a ser cuestionada durante la Gran Guerra, coincidiendo con la construcción de los primeros grandes saltos hidráulicos en España, cuando se divulgaron algunas ventajas del doble aprovechamiento, energético y de riego, y la colaboración, por tanto, entre usos y usuarios. Esta perspectiva la reclamaron, entre otros, Prado-Palacio, Huguet del Villar y Lorenzo Pardo ${ }^{49}$, cuando con el advenimiento de la Dictadura la Política Hidráulica adquirió un renovado impulso en el marco de un Ministerio de Fomento volcado en la obra pública ${ }^{50}$, el

46 ORTEGA Nicolás, «La política hidráulica», pág. 162.

47 Estos procedimientos dependían de quién tomaba la iniciativa: el Estado, auxiliado por las comarcas; las Asociaciones de regantes con el auxilio del Estado, o exclusivamente por el Estado. VillanueVA, Gregoria, La «política hidráulica» durante la Restauración, pág. 161. La Ley Gamazo de 27 de julio de 1883 había señalado la subvención en metálico de hasta un 30 por 100 del presupuesto de las obras y un premio según la cantidad de agua utilizada y la Ley de 7 de julio de 1905 también se refería a la concesión de auxilios a los aprovechamientos de aguas públicas para riegos, otorgándolos por hectárea regada. MARTín-Retortillo, Sebastián, Aguas Públicas y Obras Hidráulicas, Estudios Jurídico-Administrativos, Madrid, Tecnos, 1966, págs. 30, 42, 45 y 90.

${ }^{48}$ Gasset había promulgado su plan desde las filas del partido Conservador y luego se había unido al Partido Liberal que, desde entonces, secundaba sus propósitos. VillanueVA, Gregoria, La "política hidráulica» durante la Restauración, y ORTEGA Nicolás, «La política hidráulica».

49 Prado y Palacio, José del, Hagamos Patria. Estudio político y económico de problemas nacionales de inaplazable solución, Madrid, Tip. Artística, 1917. HugueT DEL VILLAR, Emilio, El valor geográfico de España. Ensayo de Ecética, Madrid, 1921 (reed. por Enric Tello y Carles SudRiÀ, Barcelona, ed. UB, 2010). Lorenzo PARdo, Manuel, La Confederación del Ebro: nueva política bidráulica, Madrid, Compañía General de Artes Gráficas, 1930, pág. 132.

${ }^{50}$ La obra del Ministerio de Guadalhorce ha sido analizada pródigamente. Una visión favorable a su labor, pero que hace inteligible su trayectoria, en MARTín GAITE, Carmen, El Conde de Guadalhorce. Su época y su labor, Madrid, Colegio de Ingenieros de Caminos, Canales y Puertos, 1977, págs. 1-156. La labor de las Confederaciones, en FERNÁNDEZ CLEMENTE, Eloy, Un siglo de obras bidráulicas en España. Y FERNÁNDEZ ClemenTE, Eloy, «La Confederación Hidrográfica del Ebro: la institución y su capital humano», en PINILLA, Vicente, Gestión y usos del agua en la cuenca del Ebro, págs. 133-174. 
marco legal se mantuvo, de modo que el Plan y la Ley Gasset siguieron en vigor, pero pronto se fraguaron grandes cambios, el primero de los cuales fue la constitución, a partir de 1926, de las Confederaciones Hidrográficas ${ }^{51}$. Estas sustentaban una visión plural del territorio, aunque armónica, impulsando la colaboración entre utilizadores. Las Confederaciones perseguían el entendimiento entre usos - agrícolas, arbóreos, industriales - y usuarios rivales en cada cuenca ${ }^{52}$.

Pese a sus intenciones expresas, la Dictadura se saltó en seguida el paso lento del consenso que marcaba el calendario de las Confederaciones, favoreciendo algunos intereses del sector eléctrico. Con los decretos de concesión de auxilios a determinadas compañías, para subvenir el levantamiento de diques, el Estado se convertiría así en el principal promotor de grandes embalses, cuyos saltos a pie de presa se explotarían por las empresas concesionarias, confiando a las compañías eléctricas el papel que hasta entonces, y por la Ley Gasset, se reservaba a las asociaciones de regantes ${ }^{53}$.

Esta igualación entre compañías eléctricas y comunidades de regantes convenció a pocos, como quedó claro en los dos últimos congresos de riegos. En el IV Congreso Nacional de Riegos, celebrado en Barcelona en 1929, Pedro González Quijano, responsable del embalse de Guadalcacín, se encargó de una ponencia sobre las relaciones entre aprovechamientos industriales y de regadío ${ }^{54}$. Pese a mostrarse como firme defensor del imperativo de la construcción hidráulica, apreciaba ya las contradicciones surgidas por la proliferación y simultaneidad de usos hidráulicos, proponiendo la simple regla general de preferir los aprovechamientos industriales en la región superior de las cuencas y los de riegos en las inferiores. Observaba asimismo que, en las regulaciones de caudal, las soluciones eran distintas, pues los embalses industriales garantizaban mucha agua en invierno y primavera, en su mayor parte perdida para el riego; en la regulación agrícola, se tendría en verano y otoño una abundancia de energía difícil de colocar en el mercado ${ }^{55}$. Los embalses de riego, además, solían ser mayores que los energéticos. A su juicio, siempre que hubiere conflicto, debían preponderar los intereses agrícolas ${ }^{56}$. Al hilo de la Ponencia, Vicente Burgaleta presentó una Comunicación en la que hacía constar que el problema

${ }^{51}$ El decreto de creación fue de 5 marzo de 1926. Melgarejo, Joaquín, «De la política hidráulica a la planificación hidrológica. Un siglo de intervención del Estado», en BARCIELA, Carlos y Melgarejo, Joaquín, El agua en la historia de España, págs. 275-324.

52 A juicio de Ortega, Nicolás, «El plan nacional».

53 Peralba, Antonio S., «Política Hidráulica. El Estado, las grandes obras hidráulicas y la producción de energía eléctrica», Revista de Obras Públicas, 79 (1931), t-1, págs. 71-74; 90-93 y 118-120.

${ }^{54}$ En el Congreso de Sevilla de 1918, había quedado establecido el principio de máxima utilidad social como norma única para determinar la preferencia entre aprovechamientos.

55 GonZÁlez Quijano, Pedro M., «Relaciones entre los aprovechamientos industriales y los de regadío», en IV Congreso Nacional de Riegos celebrado en Barcelona en 1927. Actas, Barcelona, Bayer Hnos. y Cía., 1929, t.11, pág. 155.

56 Aunque los usos industriales debían prevalecer sobre la navegación. GONZÁLEZ QuiJANO, Pedro M., «Relaciones entre los aprovechamientos industriales», págs. 142, 143 y 150. 
de la producción de energía no era de disponibilidad sino de coste del servicio. A su juicio, las concesiones de fuerza a las pequeñas centrales - con riego o sin él-no merecían ser consideradas, pues la energía se obtendría de forma más económica por medio de combustibles fósiles; sin embargo, la predilección ciega por los embalses de riego haría peligrar la construcción de grandes centrales hidráulicas, capaces de presentar grandes rendimientos y costes muy bajos de la energía $^{57}$. En el siguiente Congreso, celebrado en 1934 en Valladolid, Pedro Martín Martín intentó un cálculo del valor comparativo de los aprovechamientos hidráulicos para usos energéticos o agrícolas. Según sus cifras, calculadas para riego en una zona de pobre rendimiento, como es Castilla la Vieja, solo los saltos mayores de 500 metros aventajarían a su uso alternativo para riegos ${ }^{58}$. Obviamente, esta regla general tan favorable a los usos agrícolas expresaba con contundencia una opinión muy extendida.

De hecho, las ayudas a la construcción fueron suspendidas en enero de 1931 y, una vez proclamada la II República, en junio, se suprimió el funcionamiento de las Confederaciones y, en Diciembre, Prieto, como ministro de Fomento, ordenó, a través de la Orden Ministerial de 4 de febrero de 1932, que la Dirección General de Obras Hidráulicas formara un Plan General, creándose el Centro de Estudios Hidrográficos. El 31 de mayo, Prieto llevó a Cortes el Plan que firmó Lorenzo Pardo. Allí se concentraba por vez primera abundante información hidrográfica, a cargo de los servicios del Ministerio, y tres monografías -edafológica, agronómica y forestal. Se formulaba así un proyecto de corrección de los desequilibrios hidrológicos de la Península Ibérica a favor del Levante español, en tanto los rendimientos de aquel suelo eran los más favorables para aumentar las exportaciones agrarias. El Plan de Lorenzo Pardo abogaba por el uso de un nuevo tipo de infraestructura hidrográfica como herramienta esencial de su política: el trasvase ${ }^{59}$.

El Plan de 1933 desató un intenso debate por el que las regiones menos favorecidas reclamaron el restablecimiento del Plan de 1902. El sector hidroeléctrico se destacó en ese grupo de descontentos. El Plan General de Obras Hidráulicas mostraba un perfil agrarista, insistiendo en que los vasos hidroeléctricos inundaban fértiles valles y dificultaban la localización alternativa de embalses para regadío aguas abajo ${ }^{60}$. Como una paradoja más, Melgarejo señala, sin embargo, que entre 1934 y 1939, el destino mayoritario de los embalses

${ }^{57}$ BuRgaleta, Vicente, «Voto particular referente a las conclusiones $6^{\mathrm{a}}$ y $13^{\mathrm{a}}$ de la Ponencia de González Quijano del tema II», en IV Congreso Nacional de Riegos celebrado en Barcelona en 1927. Actas, Barcelona, Bayer Hnos. y Cía, 1929, t.11, pág. 238.

${ }^{58}$ MARTín MARTín, Pedro, "Relaciones económicas entre los aprovechamientos industriales y agrícolas», en V Congreso Nacional de Riegos, celebrado en Valladolid en 1934. Actas, Valladolid, Imprenta Castellana, 1935, vol. 1, pág. 423.

59 Ministerio De Obras Públicas, Plan Nacional de obras hidráulicas, Madrid, Suc. De Rivadeneyra, 1934.

60 SANCHEZ CuERVO, Luís, «La situación actual», pág. 8. 
construidos fue el hidroeléctrico, pues nueve presas acabaron destinadas a este fin, aunque solo una de todas las erigidas estuviera incluida en el Plan de 1933 y, como se verá, con escaso apoyo público ${ }^{61}$.

\section{LAS REALIZACIONES (I): LA CONSTRUCCIÓN DE DIQUES ELÉCTRICOS Y LA LEY GASSET}

La Ley Gasset de 1911 estableció subvenciones a la construcción de obras hidráulicas con destino a riegos, defensas y encauzamiento de las corrientes previendo en su artículo 12 un procedimiento en caso de que la ejecución corriera a cargo de los interesados: recibir una subvención del 50 por 100 del valor de la obra y un anticipo del 40 por 100 por parte del Estado. Los promotores debían organizarse necesariamente en mancomunidades o asociaciones de regantes y adelantar el 10 por 100 del coste total de la obra de regulación de caudales ${ }^{62}$. Su incidencia fue intensa, como ha mostrado Herranz, pues la capacidad de almacenamiento de los embalses españoles se sextuplicó entre 1912 y $1923^{63}$. La literatura jurídica ha insistido en su escaso efecto sobre el riego y, en contraste, algunos ejemplos de beneficiarios hidroeléctricos ${ }^{64}$. Se ha invocado con frecuencia la acción de Rafael Benjumea, que luego sería conde de Gualdalhorce, quien supo sacar provecho de esta Ley con la construcción del embalse de Chorro. Este vaso de almacenamiento hidráulico contó inicialmente con la presa y el aprovechamiento eléctrico de Chorro (1914-1921), y luego Gaitanejo (1927). A raíz de las inundaciones que afectaron Málaga en 1911 y, dada su influencia en la comarca, Benjumea logró que prosperase su iniciativa de crear el Sindicato Agrícola del Guadalhorce, que se acogió a la Ley de auxilios para poner en riego $22.000 \mathrm{Ha}^{65}$. La compañía que estaba a su cargo, La Sociedad Hidroeléctrica del Chorro, adelantó el 10 por 100 del importe de las obras del

${ }^{61}$ Melgarejo, Joaquín, «De la política hidráulica a la planificación hidrológica», pág. 298.

62 Villanueva, con datos oficiales, estima que entre 1904 y 1923 se pusieron en riego al menos $288.146 \mathrm{Ha}$ y, además, buena parte del riego eventual se transformó en riego constante. Villanueva, Gregoria, La «política hidráulica» durante la Restauración, pág. 218. Melgarejo, tomando estimaciones de Martín Mendiluce calcula que, a lo largo del siglo XX, el incremento del regadío en España fue de más de un millón y medio de $\mathrm{Ha}$, tomando como punto de referencia esta Ley de Grandes Regadíos de Gasset. Melgarejo, Joaquín, «De la política hidráulica a la planificación hidrológica, pág. 286.

63 Pasó de 150 a $929 \mathrm{Hm}^{3}$ de capacidad. Herranz, Alfonso, La dotación de infraestructuras en España, cuadro II.11, pág. 77.

${ }^{64}$ FANLO, Antonio, Las confederaciones hidrográficas, pág. 85.

${ }^{65}$ La primera central hidroeléctrica se inauguró en 1905, pero el proyecto de regulación se pospuso hasta 1913 y fue autorizado por R. O. de 20 de agosto de 1914 (Gaceta del 21) y por R. O. de 5 de diciembre del mismo año se conformó el Sindicato. La empresa eléctrica asumió el 10 por 100 del adelanto del presupuesto, y siguió haciéndolo hasta el 21 de mayo 1921, tras el embalse de 80 millones de $\mathrm{m}^{3}$ de agua. MARTín GaITE, Carmen, El Conde de Guadalhorce, pág. 45. 
embalse a cambio de la disponibilidad ilimitada de las aguas para la explotación de $9.500 \mathrm{~kW}$ en $1935^{66}$.

Ahora bien, si se atiende a otras evidencias, se diría que el caso de Chorro fue más bien la excepción. En primer lugar, el riego fue la prioridad del almacenamiento de agua en España hasta 1920. Entre 1910 y 1920, en que la capacidad total de embalse se cuadruplicó ampliamente, el porcentaje de aquella destinada a riegos se mantuvo en torno a la mitad del total y en 1925 suponía aún un tercio $^{67}$. En segundo lugar, el presupuesto efectivo para obras hidráulicas —embalses y canales - fue siempre muy limitado. Pese a los discursos grandilocuentes, Villanueva comprobó que el presupuesto del Ministerio de Fomento para Obras Hidráulicas superó un solo año el 2 por 100 de los presupuestos generales del Estado —en el ejercicio a caballo entre 1921 y 1922 - y únicamente sobrepasó el 1 por 100 a partir de 1911, manteniéndose entre 1 y 2 hasta $1923^{68}$. En tercer lugar, Ortúñez ha mostrado, haciendo uso de las estadísticas de Obras Públicas, que las cantidades invertidas por el Estado en obra hidráulica entre 1914 y 1916 lo fueron casi en un 96 por 100 a título propio ${ }^{69}$. Las cantidades abonadas a empresas particulares durante esos tres años — como anticipo o subvención- alcanzaron la escasa cifra de 621.738,22 Pta. ${ }^{70}$.

Se podría alegar la falta de representatividad del breve período para el que se disponen datos desglosados del gasto en obra hidráulica; sin embargo, en la Cuenca del Ebro, bien estudiada al respecto, entre 1911 y 1926 predominaron todavía los embalses para riego, cuya capacidad de embalse suponía un tercio del total español para el conjunto de usos en $1920^{71}$. En el Alto Ebro, Garrués contabiliza cinco embalses de uso eléctrico en funcionamiento con anterioridad al conflicto civil, de los cuales solo dos, el de Leurza de Hidroeléctrica Ibérica, y el Salto del Cortijo se construyeron antes de la Dictadura y se ejecutaron por las propias hidroeléctricas que, además, asumieron el coste de la obra civil ${ }^{72}$. Otro

${ }^{66}$ Bernal, Antonio Miguel, «Historia de la Compañía Sevillana de Electricidad (18941983)», en AlCAIDE, Julio, Compañía Sevillana de Electricidad. Cien años de Historia, Sevilla, Fund. Sevillana de Electricidad, 1994, págs. 233 y 234. La potencia, COPDE, Datos Estadístico técnicos de las centrales eléctricas españolas correspondientes a 1935, Madrid, La Cámara, 1936.

${ }^{67}$ Herranz, Alfonso, La dotación de infraestructuras en España, pág. 77.

68 VillanueVa, Gregoria, La «política bidráulica» durante la Restauración, pág. 246, Apéndice 5.

69 OrtúñEZ, Pedro Pablo, «Reducción de competencias, mantenimiento del gasto: 19141936», Transportes, Servicios y Telecomunicaciones, 2 (2002), págs. 113 y 114. Cuadro 5.

70 A precios del aprovechamiento contemporáneo de Tremp - 58 Pta. de $1916 \mathrm{el} \mathrm{m}^{3}$ — daba para 10.719,62 $\mathrm{m}^{3}$ de presa de embalse. Esto era suficiente para construir aproximadamente dos de los pequeños saltos de Capdella, pero Tremp, por ejemplo, sumaba $275.000 \mathrm{~m}^{3}$ de hormigón en la presa.

${ }^{71}$ La capacidad de almacenamiento de los embalses para riego en 1920 en la Cuenca del Ebro era $333,2 \mathrm{Hm}^{3}$, cuando el total español era $681,1 \mathrm{Hm}^{3}$. PINILLA, Vicente, Gestión y usos del agua en la cuenca del Ebro, pág. 317. GERMÁN, Luís, «Infraestructuras hidráulicas en Aragón durante el siglo XX», en PInILla, Vicente, Gestión y usos del agua, pág. 249.

${ }^{72}$ GARRuÉs, Josean, «El desarrollo de las infraestructuras hidráulicas del Alto Ebro en el siglo XX», en PinilLa, Vicente, Gestión y usos del agua, págs. 224 y 236. 
tanto sucedió en Aragón, donde, según Germán, únicamente se terminó el pequeño embalse de Pineta, por Hidroeléctrica Ibérica ${ }^{73}$. En Cataluña, sí se ejecutaron obras de regulación hidráulica de importancia, entre ellas las de Talarn y Camarasa, 1916 y 1920 respectivamente, y cuya capacidad de embalse alcanzaba los $368 \mathrm{Hm}^{3}$, pero la iniciativa de la regulación, y su financiación, corrieron a cargo de las compañías eléctricas ${ }^{74}$.

Los testimonios coetáneos también refieren cómo los costes de la obra civil los acometieron las propias empresas eléctricas en solitario. Según los antecedentes que se publicaron en el Plan de 1933, de los contenidos en el Plan de 1902 y sus sucesivas ampliaciones, hasta 1926 solo se habían llevado a término dos pequeños embalses de uso hidroeléctrico, ambos sobre el Tajo: la presa de Bolarque y la presa de Aldeanueva en Cáceres ${ }^{75}$. A estos habría que sumar el malagueño Pantano del Chorro, que se incorporó al Plan de Obras Hidráulicas en 1919, y del que en 1923 se habían ejecutado tan solo 6.778.883 Pta. de las 16.858.527 Pta. en que se presupuestaba su obra civil en aquella fecha ${ }^{76}$.

A la vista del cuadro 2, se confirman las escasas realizaciones de la Ley Gasset respecto de la regulación con fines eléctricos. Entre 1911 y 1926, las localizaciones más apropiadas para la obtención de energía eléctrica en poco coincidían con las más aptas para el riego, que eran las que se primaban con subvenciones. Hasta 1926, solo la mitad de los $\mathrm{Hm}^{3}$ embalsados en España tenían empleo eléctrico o mixto, pero en 1935 más de dos tercios de toda la capacidad de los embalses españoles lo era para uso eléctrico o mixto, aunque ambos empleos no resultaran siempre simbióticos ${ }^{77}$.

Hasta 1935, no abundaron los embalses para uso mixto (Véanse cuadros 2 y 3) y, cuando así se empleaban, la capacidad unitaria de generación de la maquinaria eléctrica en uso era significativamente menor —un 20 por 100 - que en los vasos para uso únicamente hidroeléctrico. En primer lugar, los vasos para riego se ubicaban mayoritariamente en los cursos medios de las corrientes, donde la pendiente era menor y admitían maquinaria eléctrica menos potente. En segundo lugar, los tiempos de evacuación del agua necesaria para el riego no solían coincidir con los flujos de la demanda eléctrica y exigían obras onerosas. Solo en obra civil el coste por $\mathrm{kW}$ instalado en los embalses de uso mixto era siete veces mayor que en las presas para uso eléctrico antes de 1936 (Véase el cuadro 3) ${ }^{78}$.

73 GERMÁN, Luís, «Infraestructuras hidráulicas», págs. 249 y 256.

74 RAMON, Josep M., «Infraestructuras hidráulicas y regadío en la cuenca catalana del Ebro, 1850-2000», en Vicente PinILLA, Gestión y usos del agua, pág. 290.

75 Ministerio de Obras Públicas, Plan Nacional de obras hidráulicas, vol. II, Anejo II, págs. 53-69.

76 Villanueva, Gregoria, La «política hidráulica» durante la Restauración, pág. 244.

77 En 1925, el total de los vasos de almacenamiento dotados de presa admitían 985,38 $\mathrm{Hm}^{3}$ cuando aquellos con aprovechamiento eléctrico solo alcanzaban $570 \mathrm{Hm}^{3}$. En 1935 de los 3.896 $\mathrm{Hm}^{3}$ de capacidad de los embalses españoles, $2.552 \mathrm{Hm}^{3}$ eran para empleo eléctrico o mixto. Los embalses españoles, en HERrANZ, Alfonso, La dotación de infraestructuras en España, pág. 77.

78 Desde la Ley de 24 de agosto de 1933, estaban obligados a satisfacer un canon como beneficiarios de la regulación. MARTín-Retortillo, Sebastián, Aguas Públicas y Obras Hidráulicas, pág. 90. 
Tras la guerra civil, en los tiempos de escasez de la posguerra, 14 embalses construidos con anterioridad a 1936 fueron reconvertidos para incluir el uso eléctrico. Su capacidad de almacenamiento de agua era algo mayor que aquella de los vasos empleados en 1935 para uso mixto, pero la potencia hidroeléctrica instalada no alcanzaba la mitad de aquélla ${ }^{79}$. Y, por consiguiente, el coste de la obra civil por $\mathrm{kW}$ instalado casi se duplicaba, a precios de 1931: 1.091 Pta.

CUADRO 2. ESTIMACIÓN POR PERÍODOS DEL COSTE DE LA OBRA CIVIL DE LOS EMBALSES CONSTRUIDOS EN ESPAÑA HASTA 1935 EMPLEADOS PARA USOS ELÉCTRICOS Y MIXTOS

\begin{tabular}{|l|l|l|l|}
\cline { 2 - 4 } \multicolumn{1}{c|}{} & $1890-1925$ & $1926-1935$ & Total \\
\hline Numero de Embalses & 20 & 13 & 33 \\
\hline Cubicaje de las presas $\mathrm{m}^{3}$ & 1.603 .209 & 1.625 .318 & 3.228 .527 \\
\hline Embalses en $\mathrm{Hm}^{3}$ & 570 & 1.982 & 2.552 \\
\hline $\mathrm{kW}$ instalados & 234.056 & 260.400 & 494.456 \\
\hline Coste en Pta. de 1931 & 492.661 .899 & 366.102 .022 & 904.626 .169 \\
\hline Coste Pta. de $1931 / \mathrm{kW}$ & 2.105 & 1.406 & 1.830 \\
\hline
\end{tabular}

Fuentes: Garrido, Manuel, «Embalses», en Universidad Comercial De Deusto, Riqueza Nacional de España, vol. 4, Bilbao, Universidad de Deusto, 1968. COPDE, Datos Estadístico técnicos de las centrales; y SINDicato Nacional de Agua, GaS y Electricidad, Datos estadístico-técnicos de las centrales; REDONET MAura, José L., Unesa. Pasado, presente y futuro de la energía eléctrica en España, Madrid, Aldus, 1947; y MINISTERIO DE Obras Públicas. Dirección General de Obras Hidráulicas, Aprovechamientos hidráulicos dotados de embalses, Madrid, Tip. Artística, 1952. Y Presas Españolas 1986: http://hispagua.cedex.es/datos. Los costes de las presas calculados a precio de la presa de Burguillo, de 1931, siguiendo el procedimiento de HerRANZ, Alfonso, La dotación de infraestructuras en España.

CUADRO 3. ESTIMACIÓN SEGÚN SU USO DEL COSTE DE LA OBRA CIVIL DE LOS EMBALSES CONSTRUIDOS EN ESPAÑA HASTA 1935

\begin{tabular}{|l|l|l|l|}
\cline { 2 - 4 } \multicolumn{1}{c|}{} & Eléctricas & Uso Mixto & Total \\
\hline Numero de Embalses & 22 & 11 & 33 \\
\hline Cubicaje de la presa m ${ }^{3}$ & 1.828 .193 & 1.400 .334 & 3.228 .527 \\
\hline Embalse en $\mathrm{Hm}^{3}$ & 1.619 & 933 & 2.552 \\
\hline $\mathrm{kW}$ instalados & 369.408 & 125.048 & 494.456 \\
\hline Coste total en Pta. de 1931 & 219.762 .320 & 537.557 .174 & 904.626 .169 \\
\hline Coste Pta. de 1931/ kW & 595 & 4.299 & 1.830 \\
\hline
\end{tabular}

FUENTES: Las mismas del Cuadro 2.

79 La capacidad de embalse se elevaba a $990 \mathrm{Hm}^{3}$ y los $\mathrm{kW}$ instalados eran 60.362. Las fuentes son las mismas del Cuadro 2. 
LAS REALIZACIONES (II): LOS ANTICIPOS REINTEGRABLES DURANTE LA DICTADURA

$\mathrm{Si}$, a diferencia de lo supuesto hasta ahora, la Ley Gasset incidió levemente sobre el sector eléctrico, el auxilio público directo tampoco tuvo más que un carácter estrictamente episódico. Las subvenciones prestadas a determinadas compañías durante la Dictadura, en 1925 y 1926, se suspendieron antes de la proclamación de la II República. Estas se habían otorgado a $S$. A. de Canalización y Fuerzas del Guadalquivir, para la construcción inmediata de los embalses de Tranco de Beas, Rumblar, Jándula y Encinarejo ${ }^{80}$; a Saltos del Alberche, refundiendo las concesiones de la Sociedad Electro Metalúrgica Ibérica, por los embalses del Burguillo y del Charco del Cura ${ }^{81}$ y, una vez ya construido, se había concedido una ayuda a la Unión Española de Explosivos por el embalse de Camporredondo ${ }^{82}$. Se subvencionó asimismo el Pantano de la Toba a la Electra de Castilla, que, junto con Saltos del Alberche, eran filiales de UEM, pero las obras comenzaron con posterioridad ${ }^{83}$. La novedad de estas ayudas consistía en que sus beneficiarias eran las propias compañías hidroeléctricas sin intermediación de las mancomunidades de regantes, como indicaba la Ley de 1911. No obstante, la explotación hidroeléctrica se consideraba aún supeditada a aquella agrícola y la obra civil revertiría al Estado pasados 20 años. Este último subvencionaba el 50 por 100 de la ejecución de los embalses más un 5 por 100 por gastos de dirección y administración. Anticipaba asimismo un 40 por 100 del presupuesto, reembolsable en 20 años a un interés del 3 por 100 anual. En caso de que hubiera retrasos en el pago, el concesionario recibiría un 5 por 100 de interés adicional sobre sus adelantos. Exceptuado el embalse, el resto de la obra civil y la maquinaria eran por cuenta exclusiva de la compañía eléctrica ${ }^{84}$.

Estos decretos de concesión de auxilios se derogaron en enero de $1931^{85}$. El gobierno provisional de la II República, en 20 de abril de 1931, estableció un período que finalizaba el 29 de enero de 1934 para su eventual declaración

${ }^{80}$ R. D. de 25 de abril de 1925 y R. D. Ley de 29 de abril de 1925.

${ }^{81}$ R. D. 25 de junio de 1926.

82 R. D. de 25 de junio de 1926

83 Peralba incluyó el Pantano de Bachende, en el Esla, pero ninguna otra fuente lo corrobora. Peralba, Antonio S., «Política Hidráulica. El Estado», pág. 74. Sí se tiene constancia de que Hidroeléctrica Española solicitó a título propio el embalse de la Fuensanta, y le fue concedido en 1927, pero traspasó sus derechos a la Confederación Hidrográfica del Segura, que lo empleó para riego. Según las Memorias de la compañía, referidas por TedDe, Pedro y AUBANELl, Anna M., «Hidroeléctrica Española (1907-1944)», en ANES, Gonzalo, Un siglo de luz. Historia empresarial, pág. 233. Garrués señala que la Confederación Hidrológica del Ebro y Fensa recibieron un millón de Pta. —una séptima parte del presupuesto - por la construcción del Embalse de Alloz, pero, aunque se inauguró en 1930, lo era para un aprovechamiento mixto, siguiendo la Ley Gasset de 1911. GARRUÉs, Josean, «El desarrollo de las infraestructuras hidráulicas», pág. 234 y ERRANDONEA, Esteban, "Aprovechamiento hidroeléctrico del río Salado en Alloz», ROP, 79 (1931), t. 1, págs. 477-483.

84 Peralba, Antonio S., «Política Hidráulica. El Estado», pág. 73.

85 R. D. de Fomento de 10 de enero de 1931 (Gaceta del 11). 
como lesivos del interés público ${ }^{86}$. No habiéndose tramitado en aquel plazo la declaración, las concesiones se convirtieron en firmes, aunque no así el cobro de auxilios y subvenciones. Así, en el caso de Saltos del Alberche, de las 27.612.151,17 Pta. a que ascendía el monto total de lo concedido a esta compañía por las obras de los embalses construidos, solo se habían librado un total de 7.020.527,30 Pta. en 31 de diciembre de 193087. El descubierto del Estado, por su auxilio o subvención, sumaba 9.560.184,13 Pta. y el anticipo reintegrable del Estado, recibido por la sociedad, ascendía a pesetas 3.120.234,35 Pta. El 31 de diciembre de 1933, el descubierto del Estado por su auxilio acumulaba 20.613.991,75 Pta. y el anticipo reintegrable del Estado, recibido por la sociedad no se había alterado. El 29 de enero de 1934, vencido el plazo otorgado por el Gobierno Provisional de la República, al que las Cortes Constituyentes dieron fuerza de ley, sin que se declarara lesiva del interés público la concesión otorgada a la empresa por la Dictadura, Saltos se dirigió al Ministro de Obras Públicas solicitando el cumplimiento por parte del Estado de sus compromisos con la entidad. El expediente pasó a informarse por el Consejo de Estado, pero las instalaciones - excepto el Charco del Cura - acabaron siendo propiedad de la UEM, que se hizo cargo desde 1933 del servicio financiero de las obras ${ }^{88}$.

En el caso de Canalización y Fuerzas del Guadalquivir, S. A., la suma de los anticipos reintegrables recibidos hasta 1934 ascendía a 10.078.520,23 Pta., pasando los embalses a propiedad de la compañía concesionaria. En total, pues, y desconociendo el monto total de la subvención directa recibida por los embalses jienenses, la Dictadura otorgó por decreto más de 21 millones de Pta. a las empresas eléctricas para la construcción de embalses, aunque fuese más lo que el Estado debiese que lo así subvencionado ${ }^{89}$.

Los técnicos del sector eléctrico fueron los primeros en abominar en esos años de lo que consideraban «alocada política hidráulica de los gobernantes». Así, Sánchez Cuervo, ilustre ingeniero, inició en 1926 una serie de artículos cuyo objeto era poner en entredicho la política de concesiones desaforadas de la Dictadura, pero, sometido a diversas presiones, debió abandonar su propósito tras publicar el segundo de los artículos anunciados ${ }^{90}$. El primero de ellos lo dedicaba a lo que él llamaba «el actual ambiente oficial», preñado del «mesianismo» de lo «gacetable». Un nuevo tipo de «arbitrismo» estaba atravesando

\footnotetext{
${ }^{86}$ De acuerdo con el preámbulo del Decreto de 6 de mayo de 1931 (Gaceta del 7), se perseguía definir un orden en el aprovechamiento hidráulico.

${ }^{87}$ Suelto, «Extracto Memoria Saltos del Alberche de 1932», Mundo Financiero, 667 (1933), pág. II.

${ }_{88}$ ABE, Dirección General de Sucursales, Leg. 3.099.

89 Ibidem. Incluyo también el millón recibido por Fensa y la Confederación Hidrológica del Ebro por la construcción de Alloz en 1930, aunque solo corresponda el período y no la finalidad de esta ayuda. GARRUÉs, Josean, «El desarrollo de las infraestructuras hidráulicas», pág. 234.

90 SÁNCHEZ Cuervo, Luís, «El problema de la energía eléctrica en España» y los publicó en Revista de Obras Públicas (1926), págs. 451-53 y 510-514.
} 
Europa en forma de «mal de la electrificación», que hacía concebir que todo el porvenir de la industria de un país tenía una encrucijada, definida por el incremento de su potencial productor de energía. A su juicio, esta observación era errónea, en tanto que no advertía cuál era la capacidad de absorción de los mercados y de inversión de las compañías y de la Hacienda:

«..¿Se trata de algo posible y conveniente, que justifique los sacrificios eventuales exigidos a la Nación? ¿Se trata, por el contrario, de utopías generosas o de agri somnia?»91.

Del mismo modo, Eduardo Gallego, en su balance anual en La Energía Eléctrica de 1927, describía cuáles habían sido estos auxilios a las distintas compañías y se lamentaba de la falta de responsabilidad que demostraban el gobierno, que estaba transido de un peculiar «delirio de grandezas de la Dictadura» ${ }^{92}$. Compartían estos términos Sintés y Vidal, quienes incluso reprodujeron algunas de estas disposiciones de auxilio de la industria para corroborar lo injustificable y desmesurado de esas ayudas ${ }^{93}$.

Más allá de estas y otras opiniones contrarias, el razonamiento por el que se ha venido explicando la interrupción abrupta de estas ayudas institucionales a la caída de la Dictadura se cimienta sobre las dificultades de la Hacienda españo$1 a^{94}$. En efecto, según Garrido Bartolomé, el coste real de La Jándula, El Encinarejo, El Burguillo, Camporredondo y La Toba, que se terminó en 1939, ascendió a 95.087.000 Pta. —88.674.200, según mis cálculos a precio de Burguillo—95. En estas condiciones, el Estado debería haber reintegrado la mitad de estos costes, en torno a 50 millones de Pta., lo que suponía más de la mitad del conjunto de subvenciones otorgadas para todo tipo de obras hidráulicas en el período de más actividad a través de terceros (1926-1929). El esfuerzo que se exigía a la Hacienda con estos auxilios era sin duda considerable ${ }^{96}$.

No obstante, durante la II República se siguió invirtiendo en obra hidráulica y mucho. Cuando Comín realizó un estado exhaustivo de la cuestión de la política de la Dictadura, puso en entredicho algunos los postulados de aquellos que establecían una cesura entre la política de la Dictadura y la República en asuntos hidráuli-

${ }^{91}$ SÁNCHEZ CuERvo, Luís, «El problema de la energía eléctrica en España», pág. 452.

92 GAllego, Eduardo, «La industria eléctrica en 1926», La Energía Eléctrica (1927), pág. 1.

${ }^{93}$ Distinguen, no obstante, entre las más tempranas, y derivadas de planes de riego a mayor escala, tales como la del Guadalquivir, de aquellas otras cuya única finalidad era favorecer la propuesta de una sociedad particular, como Saltos del Alberche. SiNTÉS y VIDAL, La industria eléctrica en España, pág. 494.

${ }_{94}$ SINTÉS y VIDAL, La industria eléctrica en España, págs. 342 y 497. GARCía DeLGADO, José Luís, «La industrialización española en el primer tercio del siglo XX», en Jover, José María, dir., Los comienzos del siglo XX: la población, la economía, la sociedad (1898-1931), Madrid, Espasa-Calpe,1984, pág. 90.

95 GARRIDO, Manuel, «Embalses», pág. 723.

96 Según Lorenzo Pardo, el presupuesto total de subvenciones hidráulicas entre 1926 y 1929 ascendió a 82.276.000 Pta. Ministerio De OBRAs PúblicAs, Plan Nacional de obras hidráulicas, pág. 56. 
cos. Para Comín, se hizo lo que se pudo, que no era mucho, y, además, se continuó haciéndolo con posterioridad al Ministerio de Argüelles ${ }^{97}$. A este respecto, Gómez Mendoza demostró cómo durante la República se mantuvo e incluso se superó el ritmo de inauguraciones de obras hidráulicas comenzado durante la Dictadura ${ }^{98}$.

A mi juicio, en la transición entre la Dictadura y la II República las que efectivamente cambiaron fueron las preferencias en la obra pública: los planes de construcción de infraestructuras para riegos continuaron a buen ritmo, pero se desgajaron de su eventual empleo industrial. Ante la disyuntiva de priorizar infraestructuras hidráulicas para uso agrario o industrial, los gobiernos republicanos se inclinaron por las primeras. Lorenzo Pardo, quien había defendido con Guadalhorce la utilización múltiple de los pantanos, estando al frente de la Confederación del Ebro, cambió su parecer, subordinando los intereses eléctricos a aquellos de los regantes y apelando reiteradamente a la Ley de Aguas y al interés privado como único responsable de la explotación eléctrica en su Plan de Obras Hidráulicas ${ }^{99}$. Muy esclarecedor es a este respecto el epígrafe que en sus Directrices dedica Lorenzo Pardo a su aspecto industrial:

«...si la iniciativa privada lo ha hecho posible a un orden del 15 por 100 entre 1918 y 1930, es mejor no interponer en su marcha una acción estatal seguramente menos viva y ágil».(...) «La electrificación de las obras regularizadoras o acaparadoras incluidas y el empleo de la energía producida, es factor económico muy importante del plan. (...)[Pero]No impone la necesidad ni aconsejan las circunstancias un plan de construcción con esa finalidad»100.

Con este giro en sus prioridades, Lorenzo Pardo simbolizó la pirueta completa, de nuevo agrarista, del regeneracionismo hidráulico español ${ }^{101}$. Así, de un lado, procuraba evitar que cayeran sobre él las críticas de despilfarro verti-

${ }_{97}$ Con datos de Lorenzo Pardo, DíAZ-MarTa, Manuel, «Evolución de las políticas hidráulicas españolas desde la Ilustración hasta nuestros días», en ARrojo, Pedro y MARTínEZ, F. Javier (eds.), Congreso ibérico sobre gestión y planificación de aguas, Zaragoza, Navarro \& Navarro, 1998, págs. 33-43. Comín, Francisco, Economía y Hacienda en la España Contemporánea, 1800-1936, Madrid, Instituto de Estudios Fiscales, 1988, pág. 1032; y véase asimismo MARTORELL LiNARES, Miguel, El santo temor al déficit: política y haciendo durante la Restauración, Madrid, Alianza, 2000, pág. 214.

98 Gómez Mendoza, Antonio, «Las Obras Públicas, 1850-1935», en Comín, Francisco, Martín Aceña, Pablo (dirs.), Historia de la empresa pública en España, Madrid, Espasa-Calpe, 1991, pág. 202 y DíAZ-MARTA, Manuel, Las obras hidráulicas, págs. 54 y 71-72.

99 La colaboración, en CANO, G., «Confederaciones Hidrográficas», en GIL OlCiNA y Morales GIL, Hitos históricos de los regadíos, págs. 309-333; y ORTEGA, Nicolás, «La política hidráulica», pág. 173. Una interpretación singular al respecto es la de VELARDE, Juan, «Ideología y sector eléctrico español», en GARCía DELGADO, José Luís (dir.), Electricidad y desarrollo económico: perspectiva histórica de un siglo, Madrid-Oviedo, Hidroeléctrica del Cantábrico, 1991, pág. 222.

${ }^{100}$ Ministerio De ObRas PÚBlicas, Plan Nacional de obras hidráulicas, pág. 103.

${ }^{101}$ Un antecedente de esta opinión, LORENZO PARDO, Manuel, La Confederación del Ebro. Una curiosa semblanza, en SÁENZ, Clemente, «Evocación del Ing. de Caminos D. Manuel Lorenzo Pardo fundador del Centro de Estudios Hidrográficos», ROP, 1971, n. ${ }^{\circ} 3072$, págs. 239-247. 
das años antes sobre Guadalhorce. Pero, de otro, adoptaba el perfil combativo de la II República frente a los intereses de las compañías eléctricas, acorde con las opiniones vertidas en los últimos Congresos Nacionales de Riegos. En su propia experiencia, al frente de la Confederación del Ebro, Lorenzo Pardo había padecido cómo se materializaban las diferencias entre regantes y compañías eléctricas. Con ocasión de su proyecto de un Ebro navegable, se topó con los intereses de la Barcelona Traction y con su decisión de construir el embalse de Mequinenza, e incluso se las tuvo que ver con Cambó ${ }^{102}$.

Con todo, un último aspecto relevante en la suspensión de estas ayudas concierne la reforma del régimen concesional de asignación de recursos hidráulicos. Como queda dicho, la concesión de los auxilios había despertado una polémica agria, pero no solo por su cuantía y su discrecionalidad en el reparto, sino además, porque se soslayaba la doctrina de la concesión rogada con carácter singular, que había consagrado la entonces vigente Ley de Aguas, resolviendo así por la vía del decreto, la adjudicación de tramos completos de corrientes a un solo adjudicatario ${ }^{103}$. Los decretos que otorgaban las subvenciones contravenían los principios de la Ley de Aguas de 1879 en tanto desposeían de sus derechos a los antiguos depositarios de los permisos y procedían a la unificación de concesiones a favor del titular de las compañías receptoras de las ayudas, favoreciendo la explotación coordinada de la cuenca, pero sin concurso previo. Esta circunstancia concurría tanto en el caso de las once concesiones previstas para la regulación del Guadalquivir, como en la refundición de aquellas dispuestas para Saltos del Alberche, pero sobre todo afectaba a Saltos del Duero que, sin serle otorgada ayuda alguna para la construcción, obtuvo la unificación de sus concesiones por R. D. de 24 de agosto de 1926, quebrándose así uno de los principios doctrinales de la Ley de Aguas ${ }^{104}$. En prueba de esto, el llamado Decreto Guadalhorce de 1921 cayó junto a estos auxilios: se rebajó a rango reglamentario, suspendiendo las concesiones efectuadas con arreglo a esa disposición ${ }^{105}$.

${ }^{102}$ Creus, Lluís, Visió Económica de Catalunya, Barcelona, Llibr. Catalonia,1934, pág. 284 y VELARDE, Juan, «Ideología y sector eléctrico español», pág. 216.

${ }^{103}$ En las asignaciones de usos, los decretos de 1919 y 1921 habían contribuido a facilitar el procedimiento de acceso a los usuarios hidroeléctricos, que, con frecuencia, precisaban la agregación de anteriores concesiones y siempre la declaración de utilidad pública para proceder a la expropiación e inundación de terrenos. R. D. de 22 de octubre de 1918 (Gaceta de 23 de octubre) y R. D. de 14 de junio de 1921 (Gaceta del 15). Según la literatura jurídica, esta doctrina ya estaba presente en buena parte de la legislación desde 1921. El principio de las reservas del decreto Guadalhorce en su art. 7, en MArTín-Retortillo, Sebastián, Aguas Públicas y Obras Hidráulicas, pág. 181. Las Confederaciones Sindicales Hidrográficas introducían un enfoque global — funcional y territorial — de los aprovechamientos que superaba la doctrina de la concesión singular, a juicio de FANLO, Antonio, Las confederaciones hidrográficas, pág. 90.

104 Coincide GonZález Quijano Pedro M., «La administración general de Fomento y en especial de obras públicas», Conferencia, Madrid, Ramona Velasco, 1920.

105 Derogadas por el mismo R. D. de Fomento de 10 de enero de 1931 (Gaceta del 11). No obstante, cuando el 8 de septiembre de 1942 se promulgó la Ley que autorizaba construir el 


\section{NOTAS FINALES}

Al cabo, la regulación de caudales para la obtención de energía eléctrica con auxilio público no había logrado acumular en 1935 más de $70.000 \mathrm{~kW}$ de potencia instalada efectiva — menos de un 5 por 100 de la disponible en aquel tiempo- Los intereses de empresas y Administración apenas coincidieron: hasta 1926, los aprovechamientos múltiples con explotación eléctrica a pie de presa auspiciados desde los poderes públicos interesaron poco a las compañías, al acecho de saltos de gran potencial en la cabecera de los ríos; en la segunda mitad de los veinte, las empresas eléctricas viraron su centro de atención hacia saltos a pie de presa con embalse regulador interanual y esta mayor concordancia de objetivos acabó en colisión de intereses. Durante la Dictadura, bajo la premisa de la colaboración, se otorgaron ayudas discrecionales, pero, en sus postrimerías, la Administración interrumpió las subvenciones, recelando de fórmulas de cooperación en que los intereses agrarios se subordinasen a los eléctricos. Finalmente, las ayudas no se desembolsaron más que en una pequeña parte y la mayoría de las infraestructuras quedaron en manos de las compañías eléctricas. La exigente financiación de las presas para uso hidroeléctrico se compadeció mal con lo magro del presupuesto de la administración española, más aún en ausencia de un consenso similar al que alentó estas políticas en Francia o Italia.

En realidad, las compañías eléctricas españolas presionaron levemente para obtener beneficios de una política hidráulica industrialista. No se emplearon unánimemente en demandar de la Administración ayudas públicas con este fin. A diferencia de lo ocurrido en Italia, Francia, Suiza y Escandinavia, antes de la guerra civil española no existía una restricción de la oferta hidráulica semejante a la que la falta de recursos financieros y de localizaciones adecuadas provocó en aquellos países. La demanda eléctrica española crecía lentamente y se temía la sobreproducción que iba a conllevar la sola inauguración de Saltos del Duero. De hecho, las compañías que recibieron ayudas, como la UEM, eran las más deficitarias en medios de producción, aunque sirvieran mercados muy amplios.

Por lo demás, y como en el tendido de la red eléctrica nacional, se temía más que se anhelaba la intervención pública en una industria que, hasta entonces, se había desarrollado al margen de los paraguas institucionales. Solo en algunos casos excepcionales, como en la regulación del Guadalquivir, se presionó para la obtención del auxilio público, pero más para facilitar la agregación de concesiones de agua y su declaración de utilidad pública que para aco-

\footnotetext{
Pantano de Alarcón al Ministerio de Obras Públicas, eje de la redistribución hidráulica de la meseta, se prescindió una vez más de todo derecho anterior y se unificó a favor del constructor, esta vez, el Estado. Otro ejemplo en este sentido fue la concesión del Noguera-Ribagorzana a favor de ENHER. MARTíN-RETORTILLO, Sebatián, Titularidad y aprovechamiento de las aguas. Discurso leído el 29 de mayo de 1995 en el acto de su recepción como Académico de número... Madrid, Real Academia de Jurisprudencia y Legislación 1995, pág. 250, nota 231 y Comín, F., Economía y Hacienda en la España Contemporánea, nota 353, pág. 1158.
} 
meter las construcciones. Si el interés industrial en el cambio institucional era menor, es pues lógico que se impusieran los intereses agrarios en la definición de las prioridades hidráulicas en aquel período.

Recibido: 01-02-2010

Aceptado: 29-08-2011 